\title{
Clinical efficacy of emollients in atopic dermatitis patients - relationship with the skin microbiota modification
}

This article was published in the following Dove Press journal:

Clinical, Cosmetic and Investigational Dermatology

12 January 2017

Number of times this article has been viewed

\section{Sophie Seité \\ Hana Zelenkova ${ }^{2}$ \\ Richard Martin ${ }^{3}$}

'La Roche-Posay Dermatological Laboratories, Asnières, France; ${ }^{2}$ DOST, Private Clinic of Dermatovenereology, Svidnik, Slovakia; ${ }^{3}$ L'Oréal Research and Innovation, Tours, France
Correspondence: Sophie Seité La Roche-Posay Dermatological Laboratories, II 0 Avenue Henri Barbusse, 92600 Asnières, France Tel +33 | 46886544

Fax +33 | 46886688

Email sophie.seite@loreal.com
Background: We speculated that an emollient supplemented with a biomass of nonpathogenic bacteria such as Vitreoscilla filiformis (Vf), grown in a medium containing thermal spring water (LRP-TSW); (LRP-Vitreoscilla filiformis biomass [LRP-VFB]), could have a beneficial effect for patients with atopic dermatitis (AD).

Patients and methods: This double-blind, randomized, comparative study was conducted with 60 patients with moderate $\mathrm{AD}$. Before starting the study, participants were pretreated for 15 days with drug therapy to improve their SCORing Atopic Dermatitis (SCORAD) by at least $25 \%$. On Day 1, the eligible patients were randomized to either the emollient containing LRPVFB associated with mannose (Product A) or another emollient (product B) and were treated twice daily for 1 month. Recurrence of flare-ups and microbial communities were characterized from swabs taken at Day 1 and Day 28, under axenic conditions, from affected (AF) and proximal unaffected (UAF) skin areas.

Results: At Day 1, the average SCORAD of each group and the microbial communities of AF and UAF areas for each participant were similar. One month after the end of the therapeutic treatment (Day 28), the average evolution of SCORAD at Day 28 compared to Day 1 of patients treated with product A was significantly lower than that of the patients treated with product $\mathrm{B}$. A significantly increased level of Xanthomonas genus was noticed in the group treated with product A (versus product B). On the other hand, the level of Staphylococcus genus increased between Day 1 and Day 28 in the group treated with product B, but not in the group treated with product A. Interestingly, these differences were more pronounced for patients in relapse, and the associated SCORAD worsening was less in the group treated with product A versus the group treated with product $\mathrm{B}$.

Conclusion: This study demonstrated that a specific emollient containing a biomass of nonpathogenic bacteria $V f$ grown in a medium containing TSW and associated with a selected carbon source is able to normalize skin microbiota and significantly reduce the number and severity of flare-ups compared with another emollient.

Keywords: skin microbiota, atopic dermatitis, emollient, Vitreoscilla filiformis, thermal spring water, Xanthomonas genus

\section{Introduction}

Changes in the composition of microbial communities that colonize skin have been linked to several dermatological diseases, in particular atopic dermatitis (AD). ${ }^{1,2}$ Staphylococci colonization or infection has been associated with this pathology. It has been described that the proportion of Staphylococcus sequences, particularly Staphylococcus aureus, is greater during disease flares than at baseline or 
post-treatment. ${ }^{3}$ However, the change in the bacterial communities associated with $\mathrm{AD}$ and their responses to therapy remain poorly understood.

We previously demonstrated that bacterial communities vary between closest affected (AF) or lesional and unaffected (UAF) or non-lesional skin from the same individual, thus providing a deeper insight into the bacterial communities involved in the skin dysbiosis associated with $\mathrm{AD}^{4}$ We confirmed that staphylococci and a lower microbial diversity dominate lesional skin compared with adjacent UAF skin., We also showed that applying an emollient can return the compositional balance of an $\mathrm{AF}$ area to a state similar to that of a nearby UAF area. ${ }^{4}$ Last, but not the least, the proportion of a bacterial family such as Xanthomonadaceae with a keratolytic activity, which is naturally present on the skin, increased due to better access to keratin, which is favorable to their growth. ${ }^{4,5}$

Numerous clinical trials have attempted to demonstrate that supplementation with preventive probiotics (living nonpathogenic bacteria) has an action on the initial development and/or flares and severity of $\mathrm{AD}$, but the results have been controversial. ${ }^{6-11}$ However, applying prebiotics (ie, nonliving extracts from nonpathogenic bacteria) onto the skin, as it has been reported for some acute intestinal diseases and based on previous publications, ${ }^{12-14}$ has been suggested as an interesting therapeutic approach to modulate or balance the immune system and manipulate the different populations of the cutaneous microbiota. ${ }^{15}$ This hypothesis was based on results from in vitro, animal and clinical studies. An in vitro model on a reconstructed epidermis revealed that, surprisingly, lysate from the Gram-negative bacterium, Vitreoscilla filiformis $(V f)$, stimulated the $\beta$-defensin production and other innate immune defense mechanisms through activation of toll-like receptor 2 (TLR2). ${ }^{14} \mathrm{~A}$ mouse model of AD revealed that the $V f$ lysate is able to reduce clinical inflammatory symptoms and the inflammatory reaction to an allergen when it was applied, suggesting a significant modulation of the immune response. ${ }^{13}$ In addition, a randomized trial demonstrated that the severity of AD significantly improved by using a formula containing $V f$ lysate. ${ }^{12}$

Therefore, we speculated that an emollient supplemented with a biomass of $V f$ grown in a medium containing La RochePosay (LRP) selenium-rich thermal spring water (TSW; LRP-Vitreoscilla filiformis biomass [LRP-VFB]) could have a clinical value in the management of AD. Furthermore, we associated a specific carbon source, mannose, with LRP-VFB to promote the growth of members of Xanthomonadaceae family. This sugar used in laboratory culture medium has been shown to boost the growth of this bacterial family unlike other families such as Staphylococcaceae, Streptococcaceae, Corynebacteriaceae, and Propionibacteriaceae. ${ }^{16}$

\section{Patients and methods Ethics statement}

This study protocol complied with the ethical guidelines of the 1975 Declaration of Helsinki, was approved by the DOST ethical committee and was conducted according to ICH Guidelines for Good Clinical Practice. Written informed consent and photography consent were obtained from each subject before enrollment.

\section{Emollients}

The emollient A (product A) was a lipophilic cream containing $20 \%$ shea butter, $4 \%$ niacinamide, LRP thermal spring water (LRP-TSW), mannose, and a biomass of $V f$ grown in a medium containing TSW (LRP-VFB), (Lipikar Balm AP+; La Roche-Posay Dermatological Laboratories, Asnières, France). The emollient B (product B) was a commercial product prescribed for $\mathrm{AD}$ and containing triglyceride, glycerin, shea butter, and ceramide. Patients were randomized to apply either emollient A or emollient B. They were then instructed to apply their allocated product to their entire body twice daily, once in the morning and once in the evening. They were also instructed not to change their hygiene practices or to apply any other emollient (or any drugs, including corticotherapy or antibiotherapy) during the study.

\section{Patient recruitment and sampling}

This double-blind, randomized, comparative study included 60 patients ( 27 males and 33 females; aged from 6 months to 63 years) diagnosed with moderate AD. Clinical assessment of disease severity and skin microbiota sampling were conducted on three separate visits, a screening visit on January 6 or 7, 2014 (Day -15) and two visits on January 21 or 22, 2014 (Day 1) and February 18 or 19, 2014 (Day 28). At the screening visit, patients received a medical treatment (either corticoids, immunosuppressive, or phototherapy), according to the discretion of the dermatologist, to improve their SCORing Atopic Dermatitis (SCORAD) by at least $25 \%$ between Day -15 and Day 1 (Figure 1). At Day -15 , at the first visit (Day 1) and at study end (Day 28), the same investigating dermatologist evaluated the severity of symptoms using the SCORAD index and clinical signs of erythema, dryness, and desquamation of one or more typical lesional (AF) skin areas and a proximal non-lesional (UAF) site (scored as absent $=0$, light $=1$, moderate $=2$, or severe $=3$ ). Each area 


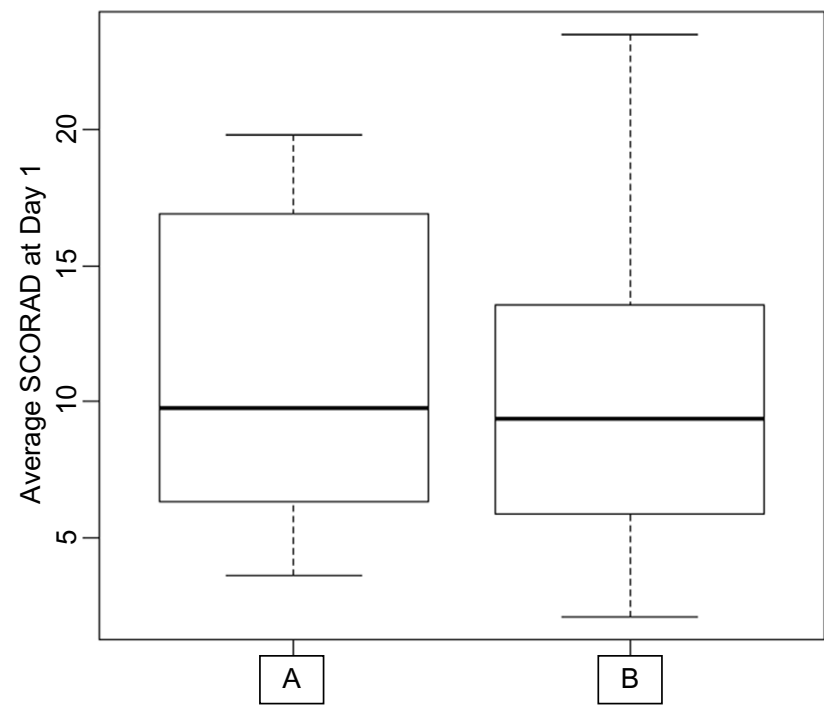

Figure I SCORAD at Day I in each treatment group $A(n=26)$ and $B(n=27)$. Notes: Bold line represents the median value $(p$-value $=0.8658)$. Group $A$ patients used product $A$ (emollient containing LRP-VFB associated with mannose) and Group $B$ patients used product $B$ (another emollient) between DI and D28.

Abbreviations: SCORAD, SCORing Atopic Dermatitis; LRP-VFB, La RochePosay-Vitreoscilla filiformis biomass.

was identified and photographed to ensure that the same area was sampled at each visit. Only individuals with SCORAD values between 0 and 40 at Day 1 and with at least a reduced SCORAD score of $25 \%$ between Day -15 and Day 1 were included in the study $(\mathrm{n}=53)$.

Skin microbiota samples were collected by the same sampler using aseptic techniques as previously described. ${ }^{4}$ Swabs were rubbed firmly for 20 seconds over $1 \mathrm{~cm}^{2}$ skin areas identified as being the most representative of AF. Similarly, samples were also collected from the closest UAF area. The cotton tip samples were stored at $-80^{\circ} \mathrm{C}$ until being shipped on dry ice to the University of Colorado for processing.

\section{DNA extraction, polymerase chain reaction (PCR) amplification, and sequencing}

Genomic DNA was extracted from each swab, and the V1-V2 region of 16S rRNA genes was amplified using PCR with the primer set $(27 \mathrm{~F} / 338 \mathrm{R}) .{ }^{4} \mathrm{All}$ sequences were processed as previously described. ${ }^{4}$

\section{Statistical analysis of clinical data}

Statistical analysis of clinical data was performed using StatView 5.0 (StataCorp LP, College Station, TX, USA). Continuous variables were described by mean and standard deviation (SD) or standard error of the mean (SEM). Qualitative variables were described by absolute numbers and corresponding percentages. Features of AD were compared at Day 1 and Day 28 using the McNemar's chi-square test.
For each feature, the number of cases with improvement was described. For quantitative values of the SCORAD, comparisons between Day 1 and Day 28 were performed by the Wilcoxon rank-sum test for paired observations. To determine the differences between product $A$ and product $B$ at Day 1 and Day 28, SCORAD and delta SCORAD values were compared using the Wilcoxon rank-sum test for paired samples.

\section{Statistical analysis of sequence data}

Statistical analysis was performed using R-2.15. Statistical tests were done on the raw count of rarefied sample (10000 reads per sample). Stratification of samples was performed using the following parameters: UAF and AF zones under A or B treatment (four groups), patient status at Day 28 compared to Day 1 (remission if SCORAD decreased or was equal between Day 1 and Day 28 (two groups) and relapse if SCORAD increased) and treatment (A or B).

\section{Results}

This study enrolled 60 patients ( 27 males and 33 females; $13 \pm 14$ years [0.5-63 years]) diagnosed with moderate form of $\mathrm{AD}$ (SCORAD =21 18 ). At Day 1, 53 patients presented with a SCORAD of $11 \pm 6$ and were included in the study (Table S1). Seven patients presented with an improvement $<25 \%$ and were excluded from the study.

After eliminating those individuals who lacked paired samples (SCORAD and microbiota) from both visits, 30 paired samples remained and were analyzed for their relation between SCORAD evolution and microbial community. Thirty-four paired samples were analyzed for microbiota communities at Day 1 and 48 paired samples at Day 28 ( $\mathrm{n}=22$ for $\mathrm{A}$ treatment and $\mathrm{n}=24$ for B treatment). Interestingly, the weight of the product used during the study was on average $192 \pm 76 \mathrm{~g}$ for product $\mathrm{A}$ and $224 \pm 102 \mathrm{~g}$ for product $\mathrm{B}(p=0.0871)$.

\section{Microbiota of UAF and AF skin at Day I}

Before any emollient treatment (at Day 1), the average SCORAD of each treatment group was similar $(11 \pm 5$ and $10 \pm 6$, respectively; $p$-value $=0.8658 ;$ Figure 1 ). The microbial communities of AF areas and closest UAF areas for each participant were also similar (Figure 2).

\section{Microbiota of UAF and AF skin at Day 28}

One month after the end of the therapeutic treatment (Day 28), the average SCORAD of the patients treated with product $A$ was lower than that of the patients treated with product $\mathrm{B}$ (SCORAD $=9.3 \pm 6.1$ and $13.2 \pm 9.6$, respectively; 


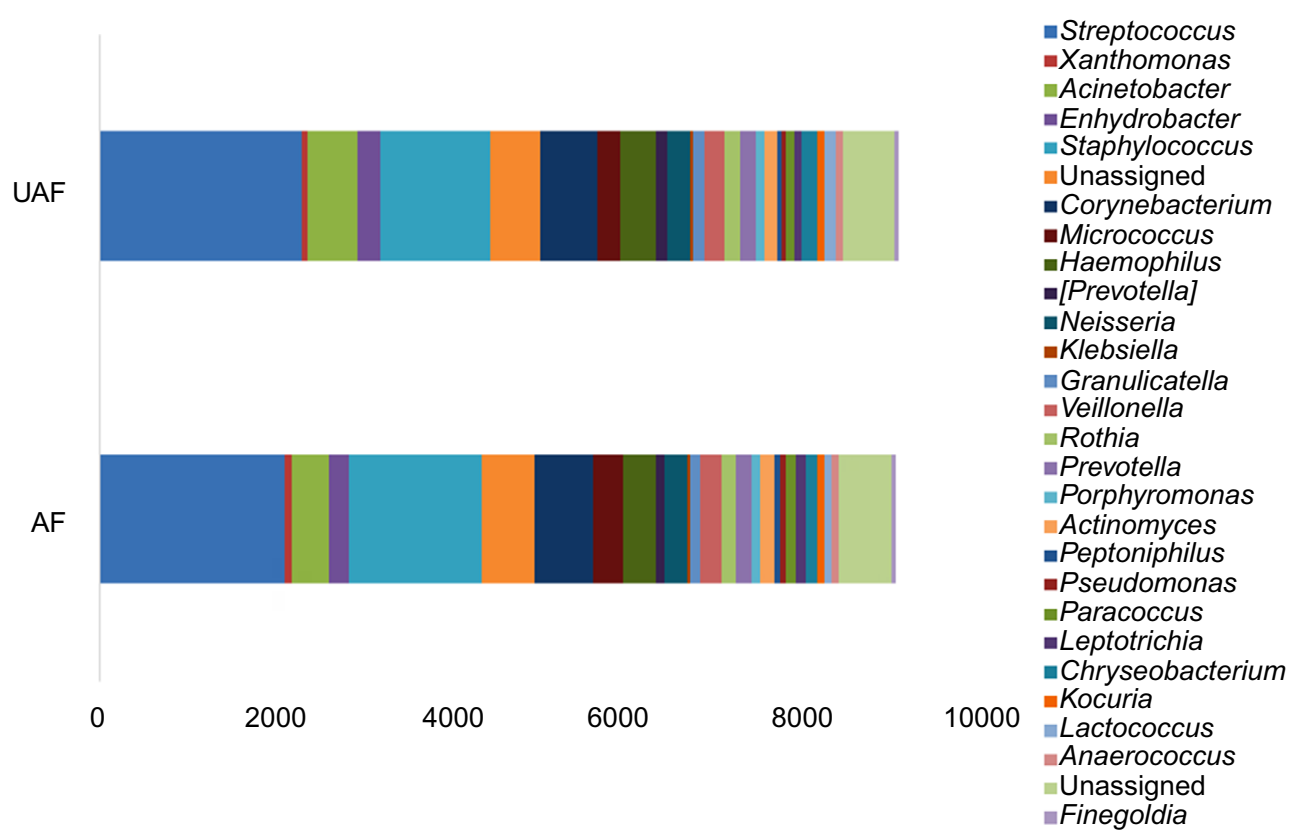

Figure 2 Average taxonomic composition ( 30 main genus) of the skin microbiota associated with UAF and AF areas in $A D$ patients at Day I ( $n=34$ ). Abbreviations: UAF, unaffected; $A F$, affected; $A D$, atopic dermatitis.

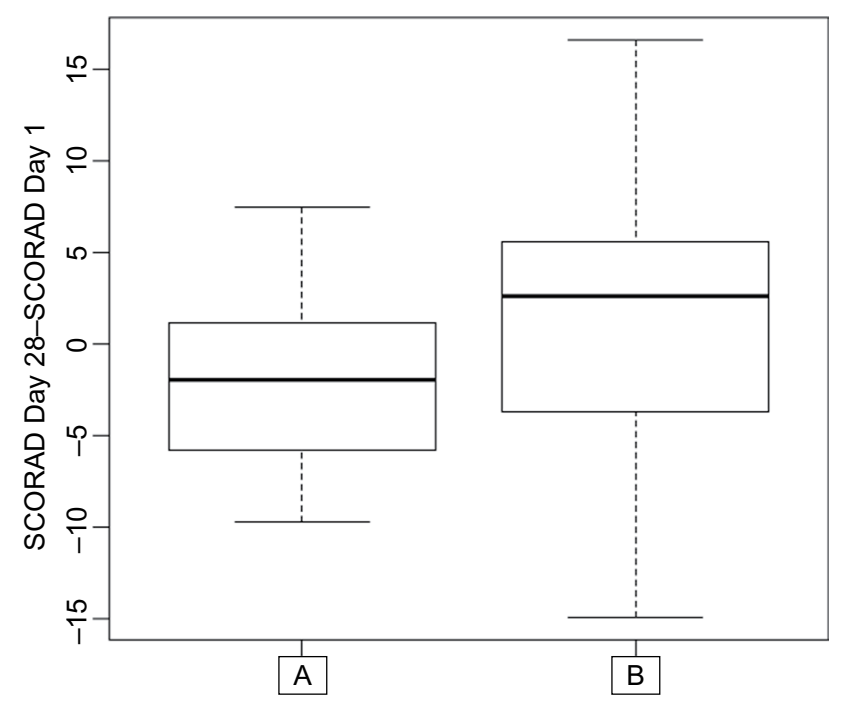

Figure 3 SCORAD variation between Day I and Day 28 in each treatment group $A(n=26)$ and $B(n=27)$.

Notes: Bold line represents the median value $(p$-value $=0.01884)$. Group A patients used product $A$ (emollient containing LRP-VFB associated with mannose) and Group $B$ patients used product $B$ (another emollient) between DI and D28.

Abbreviations: SCORAD, SCORing Atopic Dermatitis; LRP-VFB, La RochePosay-Vitreoscilla filiformis biomass.

$p$-value $=0.182$ ). SCORAD variation between Day 1 and Day 28 was significantly different between treatments ( $p$-value $=0.01884$; Figure 3$)$ corresponding to $-11 \%$ for product A versus $+35 \%$ for product B. Interestingly, in the product A-treated group, nine of the 26 patients (30\%) showed an aggravation (relapsing patients) versus 18 of the $27(60 \%)$ in the product B-treated group, and 17 of the 26 remained in remission or improved in the product A-treated group versus only nine of the 27 in the product B-treated group. Of particular note, the associated SCORAD in relapsing patients worsened less in the group treated with product A $(46 \%)$ versus the group treated with product B (79\%).

At Day 28, the microbial landscape of AF and UAF areas was similar in both groups but very different between each treatment (Figure 4). Particularly, a significantly increased level of Xanthomonas genus ( $p$-value $=2.57 \mathrm{e}-02$ ) was noticed in the group treated with product A (versus product B; Figure 5). On the other hand, the level of Staphylococcus genus increased between Day 1 and Day 28 in the group treated with product $\mathrm{B}$ ( $p$-value $=0.1534$ on UAF and $p$-value $=0.2642$ on AF), but was not observed in the group treated with product A ( $p$-value $=0.7697$ on UAF and $p$-value $=0.9729$ on AF). Interestingly, these differences in the microbial landscape were more pronounced for patients in relapse (patients with an increased SCORAD at Day 28 versus Day 1).

\section{Discussion}

Using a high-throughput sequencing approach that targets two portions of the 16S rRNA gene (V1-V2), as recommended by Meisel et al, ${ }^{17}$ to study cutaneous bacterial communities and dysbiosis associated with the severity of $\mathrm{AD}$ and comparing an AF skin area to the closest UAF area per patient is a sensitive method to evaluate product efficacy. With this approach, we have previously shown that an emollient can equalize the bacterial composition of an $\mathrm{AF}$ area to a state similar to that of an adjacent UAF area. ${ }^{4}$ Very 


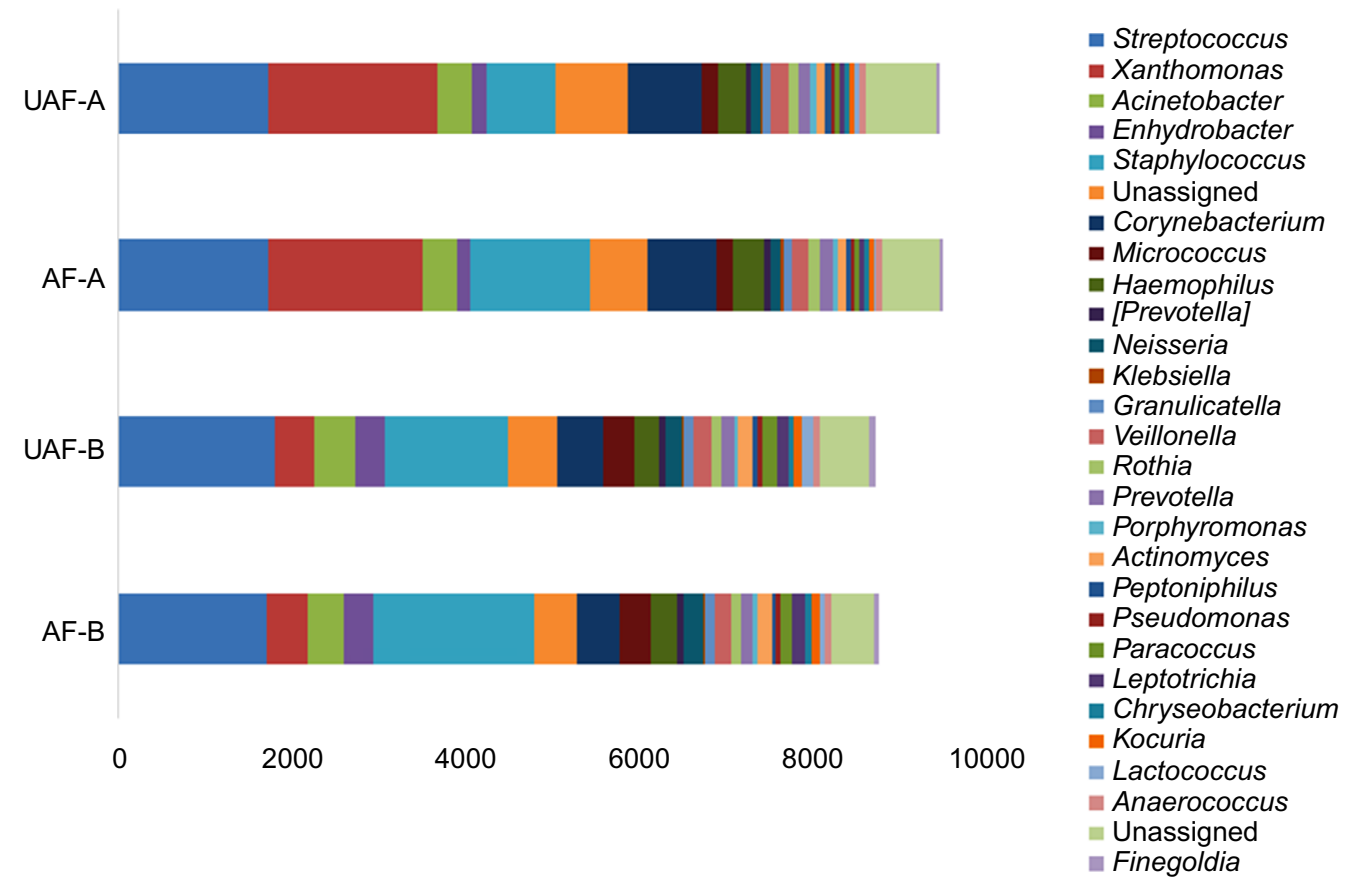

Figure 4 Average taxonomic composition ( 30 main genus) of the skin microbiota associated with UAF and AF areas in each treatment group at Day 28 ( $\mathrm{n}=22$ for product $A$ and $n=24$ for product $B)$.

Notes: Product $A=$ emollient containing LRP-VFB associated with mannose. Product $B=$ another emollient.

Abbreviations: UAF, unaffected; AF, affected; LRP-VFB, La Roche-Posay-Vitreoscilla filiformis biomass.

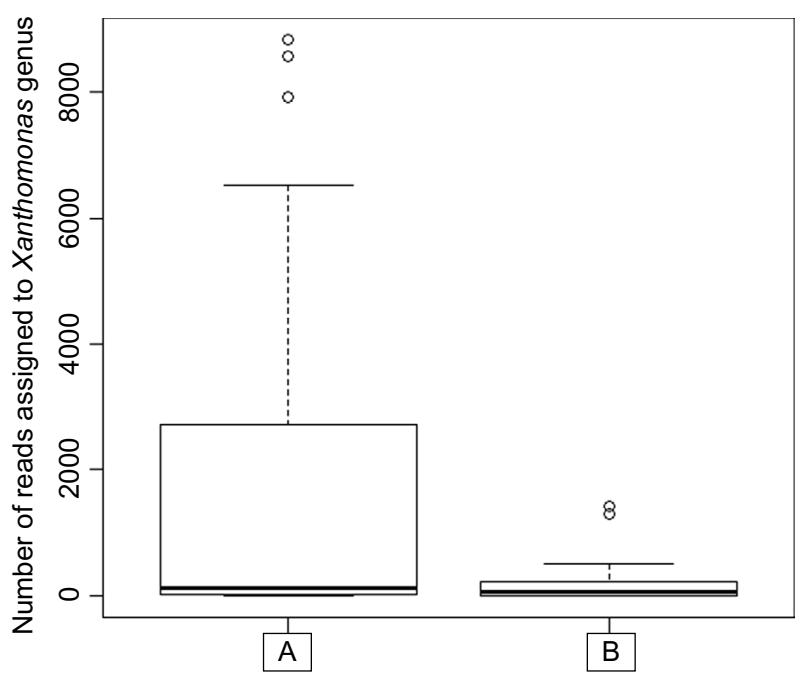

Figure 5 Xanthomonas genus in each treatment group $A(n=17)$ and $B(n=13)$. Notes: Bold line represents the median value $(p$-value $=2.57 e-02)$. Group $A$ patients used product $A$ (emollient containing LRP-VFB associated with mannose) and Group B patients used product B (another emollient) between DI and D28. Abbreviation: LRP-VFB, La Roche-Posay-Vitreoscilla filiformis biomass.

recently, the same strategy was used and exactly the same results were obtained after a 4-week treatment period with a topical corticosteroid. ${ }^{18}$

Prebiotics were initially defined as nondigestible food ingredients that beneficially affect the host by selectively stimulating the growth and/or activity of one or a limited number of bacteria. ${ }^{19}$ Prebiotics that might be included in topically applied skin products also have the potential to support normal skin microbiota maintenance or normalize dysbiosis if it occurs. ${ }^{20}$ Relatively little is known about the benefits of this approach, but it has been shown that applying a biomass lysate of the nonpathogenic Gram-negative proteobacterium, $V f$, helped to improve symptoms in patients with atopic or seborrheic dermatitis. ${ }^{12,13,21}$ It is interesting to note that VFB prepared from organisms grown in a medium enriched with TSW (LRP-VFB) resulted in more potent stimulation of mRNA expression for antimicrobial peptides and other innate immune defense mechanisms through activation of TLR2 in reconstructed epidermis. ${ }^{14}$ This original biological activity should be mainly explained by the specific structure of the lipid A moiety of the lipopolysaccharide part of $V f(V f$-LPS $){ }^{22}$

In the present study, treating the symptoms of $\mathrm{AD}$ with an emollient containing LRP-VFB and mannose as a carbon source versus another recommended emollient yielded greater clinical improvement. This was associated with a significantly increased population of Xanthomonas genus, a Gram-negative proteobacteria (Figures 4 and 5). In contrast, the comparator product was associated with an increase in Staphylococcus genus bacteria. For the first time, this study demonstrated that the topical application of a prebiotic (ie, nonliving extracts from nonpathogenic bacteria) is an interesting therapeutic approach to modulate or balance the immune system and so normalize the cutaneous microbiota for at least 1 month after the end of a therapeutic treatment. 
It is known that staphylococci are present on both healthy and AF skin of $>90 \%$ of patients with AD. This presence is at least partially explained by an antimicrobial peptide deficiency and the poor quality of the skin barrier, which allows easy access to complex substrates. ${ }^{23,24}$ Furthermore, during flares, the loss of bacterial diversity and the predominance of Staphylococcus species, Staphylococcus epidermidis and $S$. aureus, worsen in correlation with severity, ${ }^{2-4}$ as shown in this study in relapsing patients. In this study as in the two previously published ones, we highlighted that an increase in bacteria from the Xanthomonadaceae family was induced by LRP-TSW either alone ${ }^{25}$ or in high concentration in an emollient ${ }^{4}$ or with LRP-VFB and mannose. This was associated with a pathology improvement and a decrease in the proportion of staphylococci. Nevertheless, to distinguish the singular effect of each component of the product, it would be necessary to perform other in vivo and/or in vitro studies.

\section{Conclusion}

This study highlights the long-lasting efficacy for managing $\mathrm{AD}$ (reducing flare-ups and decreasing the flare severity) of a moisturizer containing emollient, humectant, moisturizing, or occlusive agents that restore skin barrier function; having acceptable cosmetic quality and excellent dermatological tolerance and supplemented with ingredients that provide nutritional supplements to revive natural cutaneous defenses and normalize the cutaneous microbiota.

These data suggest that a prebiotic made of a nonliving extract of a specific Gram-negative proteobacterium, with an original nontoxic LPS structure (ie, $V f$ ) grown in a controlled medium and associated with a selected carbon source (mannose), onto the skin is a new therapeutic approach to modulate or balance the immune system and would enable normalization of the cutaneous microbiota that could be beneficial in various immune-mediated skin diseases. This could be useful in the treatment of AD and potentially other chronic inflammatory skin diseases such as acne, rosacea, and psoriasis.

\section{Acknowledgments}

DNA extraction, PCR amplification, and sequencing were performed by Jessica B. Henley, Cooperative Institute for Research in Environmental Sciences, University of Colorado, Boulder, CO, USA. Technical support for the clinical part of the study was provided by Guénaëlle Le Dantec and Martine Fortuné. Statistical analyses were performed by Samuel Mondy.

\section{Disclosure}

This study was funded by La Roche-Posay Dermatological Laboratories and L'Oréal Research and Innovation, France. S. Seité and R. Martin are employees of L'Oréal. No conflicts of interest exists for Professor H. Zelenkova.

\section{References}

1. Grice EA, Segre JA. The skin microbiome. Nat Rev Microbiol. 2011; 9(4):244-253.

2. Grice EA. The skin microbiome: potential for novel diagnostic and therapeutic approaches to cutaneous disease. Semin Cutan Med Surg. 2014;33(2):98-103.

3. Kong HH, Oh J, Deming C, et al. Temporal shifts in the skin microbiome associated with disease flares and treatment in children with atopic dermatitis. Genome Res. 2012;22(5):850-859.

4. Seite S, Flores GE, Henley JB, et al. Microbiome of affected and unaffected skin of patients with atopic dermatitis before and after emollient treatment. J Drugs Dermatol. 2014;13(11):1365-1372.

5. Yamamura S, Morita Y, Hasan Q, Yokoyama K, Tamiya E. Keratin degradation: a cooperative action of two enzymes from Stenotrophomonas sp. Biochem Biophys Res Commun. 2002;294(5):1138-1143.

6. Panduru M, Panduru NM, Salavastru CM, Tiplica GS. Probiotics and primary prevention of atopic dermatitis: a meta-analysis of randomized controlled studies. J Eur Acad Dermatol Venereol. 2015;29(2): 232-242.

7. Muraro A, Halken S, Arshad SH, et al. EAACI food allergy and anaphylaxis guidelines. Primary prevention of food allergy. Allergy. 2014; 69(5):590-601.

8. Kim SO, Ah YM, Yu YM, Choi KH, Shin WG, Lee JY. Effects of probiotics for the treatment of atopic dermatitis: a meta-analysis of randomized controlled trials. Ann Allergy Asthma Immunol. 2014;113(2): 217-226.

9. Wang IJ, Wang JY. Children with atopic dermatitis show clinical improvement after Lactobacillus exposure. Clin Exp Allergy. 2015; 45(4):779-787.

10. Drago L, De Vecchi E, Toscano M, Vassena C, Altomare G, Pigatto P. Treatment of atopic dermatitis eczema with a high concentration of Lactobacillus salivarius LS01 associated with an innovative gelling complex: a pilot study on adults. J Clin Gastroenterol. 2014;48(suppl 1): S47-S51.

11. Niccoli AA, Artesi AL, Candio F, et al. Preliminary results on clinical effects of probiotic Lactobacillus salivarius LS01 in children affected by atopic dermatitis. J Clin Gastroenterol. 2014;48(suppl 1):S34-S36.

12. Gueniche A, Knaudt B, Schuck E, et al. Effects of nonpathogenic gramnegative bacterium Vitreoscilla filiformis lysate on atopic dermatitis: a prospective, randomized, double-blind, placebo-controlled clinical study. Br J Dermatol. 2008;159(6):1357-1363.

13. Volz T, Skabytska Y, Guenova E, et al. Nonpathogenic bacteria alleviating atopic dermatitis inflammation induce IL-10-producing dendritic cells and regulatory Tr1 cells. J Invest Dermatol. 2014;134(1):96-104.

14. Mahe YF, Perez MJ, Tacheau C, et al. A new Vitreoscilla filiformis extract grown on spa water-enriched medium activates endogenous cutaneous antioxidant and antimicrobial defenses through a potential toll-like receptor 2 /protein kinase $\mathrm{C}$, zeta transduction pathway. Clin Cosmet Investig Dermatol. 2013;6:191-196.

15. Seite $\mathrm{S}$, Bieber T. Barrier function and microbiotic dysbiosis in atopic dermatitis. Clin Cosmet Investig Dermatol. 2015;8:479-483.

16. Garrity G. Phylum Al. Crenarchaeota. In: Whitman W, editor. Bergey's Manual of Systematic Bacteriology. Vol. 1. New York, Berlin, Heidelberg: Springer; 2012.

17. Meisel JS, Hannigan GD, Tyldsley AS, et al. Skin microbiome surveys are strongly influenced by experimental design. J Invest Dermatol. 2016; 136(5):947-956. 
18. Gonzalez ME, Schaffer JV, Orlow SJ, et al. Cutaneous microbiome effects of fluticasone propionate cream and adjunctive bleach baths in childhood atopic dermatitis. J Am Acad Dermatol. 2016;75(3):481.e-493.e.

19. Gibson GR, Roberfroid MB. Dietary modulation of the human colonic microbiota: introducing the concept of prebiotics. J Nutr. 1995; 125(6):1401-1412.

20. Al-Ghazzewi FH, Tester RF. Impact of prebiotics and probiotics on skin health. Benef Microbes. 2014;5(2):99-107.

21. Gueniche A, Cathelineau AC, Bastien P, et al. Vitreoscilla filiformis biomass improves seborrheic dermatitis. J Eur Acad Dermatol Venereol. 2008;22(8):1014-1015.
22. Mahe Y, Martin R, Inventors. Lipopolysaccharide fractions of vitreoscilla filiformis useful for stimulating the synthesis of antimicrobial peptides of the skin. US Patent App. 12/055,975, 2008.

23. Ong PY, Ohtake T, Brandt C, et al. Endogenous antimicrobial peptides and skin infections in atopic dermatitis. $N$ Engl J Med. 2002; 347(15):1151-1160.

24. Nakatsuji T, Gallo RL. Antimicrobial peptides: old molecules with new ideas. J Invest Dermatol. 2012;132(3 pt 2):887-895.

25. Martin R, Henley JB, Sarrazin P, Seite S. Skin microbiome in patients with psoriasis before and after balneotherapy at the Thermal Care Center of La Roche-Posay. J Drugs Dermatol. 2015;14(12):1400-1405. 


\section{Supplementary material}

Table SI Summary of patient demographics and clinical assessment of disease severity (SCORAD) during the time course of the study (treatment $A$ in red, $n=26$, and treatment $B$ in black, $n=27$ ).

\begin{tabular}{|c|c|c|c|c|c|c|}
\hline \multirow[t]{2}{*}{ Subject } & \multirow{2}{*}{$\begin{array}{l}\text { Body site } \\
\text { sampled }\end{array}$} & \multirow[t]{2}{*}{ Gender } & \multirow{2}{*}{$\begin{array}{l}\text { Age } \\
\text { (years) }\end{array}$} & \multirow{2}{*}{$\frac{\text { SCORAD }}{\text { Day - } 15}$} & \multirow{2}{*}{$\begin{array}{l}\text { SCORAD } \\
\text { Day I }\end{array}$} & \multirow{2}{*}{$\begin{array}{l}\text { SCORAD } \\
\text { Day } 28\end{array}$} \\
\hline & & & & & & \\
\hline I & Arm & $\mathrm{F}$ & 4 & 27,5 & 13.4 & 14.6 \\
\hline 3 & Arm & $\mathrm{F}$ & 6 & 15.9 & 9.7 & 0 \\
\hline 5 & Hand & $\mathrm{F}$ & 10 & 19.4 & 6.8 & 13.2 \\
\hline 8 & Wrist & $M$ & 19 & 24.1 & 9.1 & 7 \\
\hline 10 & Neck & $\mathrm{F}$ & I & 33.2 & 19.4 & 14.5 \\
\hline 11 & Cheek & $\mathrm{F}$ & I & 28.5 & 18.6 & 21.6 \\
\hline 13 & Wrist & $\mathrm{F}$ & 16 & 27 & 12.8 & 12.7 \\
\hline 16 & Wrist & $F$ & 7 & 16.7 & 4.6 & 6.2 \\
\hline 21 & Neck & $\mathrm{F}$ & 11 & 26 & 17.8 & 13 \\
\hline 24 & Elbow fold & $\mathrm{F}$ & 5 & 22.7 & 10.6 & 16.4 \\
\hline 26 & Elbow fold & $\mathrm{F}$ & 21 & 30.4 & 14.9 & 8.4 \\
\hline 27 & Elbow fold & $\mathrm{F}$ & 2 & 13.5 & 8.8 & 5.6 \\
\hline 29 & Thumb & $\mathrm{F}$ & 2 & 31.9 & 19.8 & 12.8 \\
\hline 33 & Cheek & $M$ & 0.7 & 34.4 & 16.9 & 7.9 \\
\hline 34 & ND & $\mathrm{F}$ & 28 & 24.2 & 17.7 & 15.7 \\
\hline 36 & Elbow & $M$ & 50 & 17 & 8.4 & 0 \\
\hline 37 & Elbow fold & $\mathrm{F}$ & 43 & 14.3 & 7.9 & 4.2 \\
\hline 41 & ND & $M$ & 9 & 16.3 & 6.3 & 4.6 \\
\hline 42 & Finger articulation & $\mathrm{F}$ & 39 & 8.4 & 3.6 & 3.7 \\
\hline 43 & Elbow & $M$ & 9 & 10 & 4.3 & 4.2 \\
\hline 49 & Arm & $\mathrm{F}$ & 6 & 20.8 & 6 & 0.2 \\
\hline 51 & Arm & $M$ & 9.8 & 19.9 & 9.8 & 3.9 \\
\hline 54 & Hand & $\mathrm{F}$ & 12.3 & 23.2 & 12.3 & 17.4 \\
\hline 56 & ND & M & 18.3 & 41.6 & 18.3 & 16.4 \\
\hline 57 & Side belly & $M$ & 4.5 & 10.7 & 4.5 & 5 \\
\hline 60 & Wrist & $M$ & 5 & 10.4 & 5 & 12.5 \\
\hline 2 & Calf & $\mathrm{F}$ & 31 & 20.8 & 11.4 & 12.2 \\
\hline 4 & Hand & $\mathrm{F}$ & 25 & 19.4 & 5.6 & 18.4 \\
\hline 7 & Back & $M$ & 18 & 24.9 & 12.7 & 9.1 \\
\hline 9 & Chin & $\mathrm{F}$ & 3 & 13.5 & 8.2 & 11.5 \\
\hline 12 & Cheek & $\mathrm{F}$ & 5 & 19.4 & 8.5 & II.I \\
\hline 14 & Knee (fold) & $\mathrm{F}$ & 2 & 20 & 10.4 & 5.9 \\
\hline 17 & Elbow (fold) & $M$ & 15 & 7.4 & 7.2 & 17 \\
\hline 18 & Finger articulation & $M$ & 5 & 30.5 & 32.6 & 18 \\
\hline 22 & Elbow & $\mathrm{F}$ & 10 & 33.5 & 34.7 & 22 \\
\hline 25 & ND & $\mathrm{F}$ & $\mathrm{I}$ & 21.4 & 11.2 & 18.5 \\
\hline 28 & Elbow fold & $\mathrm{F}$ & 8 & 10.3 & 4.7 & 7.3 \\
\hline 30 & Leg & $M$ & 0.7 & 10 & 4.3 & 20 \\
\hline 31 & Forearm & $M$ & 11 & 16.6 & 7.7 & 2.5 \\
\hline 32 & Leg & $M$ & 35 & 17.6 & 8.4 & 3.7 \\
\hline 35 & Elbow fold & $\mathrm{F}$ & 29 & 14.3 & 9.4 & 0.2 \\
\hline 38 & Cheek & $\mathrm{F}$ & $\mathrm{I}$ & 28.1 & 20 & 16.3 \\
\hline 39 & Index finger & $M$ & 2 & 22 & 13 & 16.1 \\
\hline 40 & Elbow & M & 15 & 11.2 & 5.8 & 9.7 \\
\hline 44 & Thigh & $\mathrm{F}$ & I & 30.3 & 19.5 & 4.6 \\
\hline 45 & Chest (upper) & $M$ & 0.8 & 22.3 & 9.4 & 5.1 \\
\hline 48 & Arm & $M$ & 25 & 10.9 & 2.1 & I \\
\hline 50 & Chin & $F$ & 23 & 12.6 & 5.9 & 9.3 \\
\hline 52 & ND & $\mathrm{F}$ & $\mathrm{I}$ & 27.6 & 14.1 & 26.6 \\
\hline 53 & Cheek & $M$ & 7 & 29.3 & 19.8 & 20.4 \\
\hline 55 & Arm/elbow & $M$ & 16 & 20 & 10.5 & 13.9 \\
\hline 58 & Thigh & $M$ & 11 & 13.5 & 5.9 & 8.2 \\
\hline 59 & Elbow fold & $\mathrm{F}$ & 20 & 21.8 & 14.7 & 31.3 \\
\hline
\end{tabular}

Notes: Treatment $A=$ treatment with emollient containing LRP-VFB associated with mannose. Treatment $B=$ treatment with another emollient. Abbreviations: SCORAD, SCORing Atopic Dermatitis; F, female; M, male; ND, no data; LRP-VFB, La Roche-Posay-Vitreoscilla filiformis biomass. 


\section{Publish your work in this journal}

Clinical, Cosmetic and Investigational Dermatology is an international, peer-reviewed, open access, online journal that focuses on the latest clinical and experimental research in all aspects of skin disease and cosmetic interventions. This journal is included on PubMed. The manuscript management system is completely online and includes a very quick and fair peer-review system, which is all easy to use. Visit http://www.dovepress.com/testimonials.php to read real quotes from published authors

Submit your manuscript here: https://www.dovepress.com/clinical-cosmetic-and-investigational-dermatology-journal 